Pesq. Vet. Bras. 30(12):1010-1016, dezembro 2010

\title{
Alterações clínicas e patológicas em ovinos infectados naturalmente pelo vírus da língua azul no Rio Grande do Sul ${ }^{1}$
}

\author{
Nadia A.B. Antoniassi ${ }^{2}$, Saulo P. Pavarini², Luiz A.O. Ribeiro ${ }^{3}$, Mariana \\ S.Silva ${ }^{4}$, Eduardo F. Flores ${ }^{4}$ e David Driemeier ${ }^{2^{*}}$
}

\begin{abstract}
Antoniassi N.A.B., Pavarini S.P., Ribeiro L.A.O., Silva M.S., Flores E.F. \& Driemeier D. 2010. [Clinical and pathological changes in sheep naturally infected with bluetongue virus in Rio Grande do Sul, Brazil.] Alterações clínicas e patológicas em ovinos infectados naturalmente pelo vírus da língua azul no Rio Grande do Sul. Pesquisa Veterinária Brasileira 30(12):1010-1016. Setor de Patologia Veterinária, Faculdade de Veterinária, Universidade Federal do Rio Grande do Sul, Av. Bento Gonçalves 9090, Porto Alegre, RS 91540-000, Brazil. E-mail: davetpat@ufrgs.br

Bluetongue (BT) is a disease caused by bluetongue virus (BTV) and transmitted by vectors of the genus Culicoides. Serological studies have demonstrated the widespread presence of the virus in Brazil, however, clinical information of BT in South America are limited. This article describes clinical and pathological changes observed in sheep naturally infected by BTV in southern Brazil. In two outbreaks on different farms, 15 sheep showed clinical signs such as severe hyperthermia, apathy, swelling of the face and submandibular area, difficulty in swallowing with regurgitation, greenish mucopurulent nasal secretion, severe weight loss, and erosions in the oral mucosa. Necropsy findings in six sheep included subcutaneous edema of the face and ventral region of the chest, greenish nasal discharge, and dilated esophagus filled with abundant food contents, collapsed lungs with areas of anteroventral consolidation, and trachea and bronchi filled by foamy material mixed with food. In the heart and base of the pulmonary artery there were foci of hemorrhage. Histologically, the main changes were in cardiac and skeletal muscles and consisted of biphasic lesions characterized by hyaline and floccular degeneration/necrosis of myofibers associated with micro-mineralization and mononuclear cell infiltration. Pneumonia associated with the presence of organic matter and bacteria in the lumen of the bronchi was also observed. The diagnosis of BT was confirmed by detection of the viral genome by duplex RT-PCR in blood of affected animals, followed by the identification of BTV, serotype 12 by nucleotide sequencing.
\end{abstract}

INDEX TERMS: Diseases of sheep, viral diseases, bluetongue virus, Brazil.

\footnotetext{
${ }^{1}$ Recebido em 10 de julho de 2010.

Aceito para publicação em 28 de julho de 2010.

Parte da tese de doutorado do primeiro autor pelo Curso de PósGraduação em Ciências Veterinárias, área de concentração em Cirurgia, Morfologia e Patologia Animal, Universidade Federal do Rio Grande do Sul (UFRGS).

2 Departamento de Patologia Clínica Veterinária, Faculdade de Veterinária, UFRGS, Av. Bento Gonçalves 9090, Porto Alegre, RS 95320000, Brasil. *Autor para correspondência: davetpat@ufrgs.br.

${ }^{3}$ Departamento de Medicina Animal, Faculdade de Veterinária, UFRGS, Porto Alegre, RS.

${ }^{4}$ Laboratório de Virologia, Departamento de Medicina Veterinária Preventiva, Universidade Federal de Santa Maria (UFSM), Av. Roraima 1000, Santa Maria, RS 97105-900, Brasil.
}

RESUMO.- Língua azul (LA) é uma doença causada pelo vírus da língua azul (VLA) e transmitida por vetores do gênero Culicoides. Estudos sorológicos têm demonstrado a ampla presença do vírus no Brasil; entretanto, informações clínicas da LA na América do Sul são limitadas. Esse trabalho descreve alterações clínico-patológicas em ovinos acometidos pela LA no Sul do Brasil. Em dois surtos, em propriedades distintas, 15 ovinos apresentaram como principais sinais clínicos hipertermia, apatia, aumento de volume da face e região submandibular, dificuldade de deglutição com regurgitação, secreção nasal mucopurulenta esverdeada, alterações respiratórias, além de acen- 
tuada perda de peso e erosões na mucosa oral. Os achados de necropsia em seis ovinos afetados incluíram edema subcutâneo na face e região ventral do tórax, secreção nasal esverdeada, esôfago dilatado preenchido por grande quantidade de conteúdo alimentar, pulmões não colabados com áreas consolidadas anteroventrais, bem como luz da traquéia e brônquios preenchida por espuma misturada com conteúdo alimentar. No coração e base da artéria pulmonar, havia focos de hemorragia. Histologicamente, as principais alterações observadas ocorriam no tecido muscular cardíaco e esquelético, especialmente no esôfago e consistiam de lesões bifásicas caracterizadas por degeneração/necrose hialina e flocular de miofibras associadas com micro-calcificação e infiltrado inflamatório mononuclear. Pneumonia aspirativa associada à presença de material vegetal e bactérias na luz de brônquios também foi observada. O diagnóstico de LA foi confirmado pela detecção do genoma viral por duplex RT-PCR em amostras de sangue de animais afetados, seguido da identificação do VLA, sorotipo 12 por sequenciamento.

TERMOS DE INDEXAÇÃO: Doenças de ovinos, doenças virais, vírus da língua azul, Brasil.

\section{INTRODUÇÃO}

Língua azul (LA) é uma doença viral, não contagiosa, que afeta ruminantes domésticos e selvagens e é transmitida por vetores hematófagos do gênero Culicoides. A infecção causada pelo vírus da língua azul (VLA) apresenta-se, na maioria dos casos, clinicamente inaparente (Verwoerd \& Erasmus 2004, Alfieri et al. 2007, Maclachlan et al. 2009). A doença clínica ocorre principalmente em ovinos e, ocasionalmente, em outros ruminantes, e caracteriza-se por febre, lesões erosivas e ulcerativas nas mucosas do trato digestivo, hemorragias focais e necrose de músculos liso e estriado esquelético e cardíaco (Verwoerd \& Erasmus 2004, Maclachlan et al. 2009), além de alterações reprodutivas como morte embrionária, aborto e malformações fetais (Hourrigan \& Klingsporn 1975, Verwoerd \& Erasmus 2004). Os bovinos são considerados reservatórios para o vírus por apresentarem um prolongado período de viremia e raramente manifestarem sinais clínicos (Verwoerd \& Erasmus 2004). $O$ vírus está presente principalmente em áreas tropicais e subtropicas, e sua distribuição esta relacionada ao vetor e a fatores climáticos que favoreçam sua multiplicação e manutenção (Maclachlan et al. 2009). Em diversos países, já foram identificados 25 sorotipos do VLA (Holfmann et al. 2008, Maclachlan et al. 2009). Na América do Sul, informações sobre a predominância dos sorotipos são limitadas. Em 1980, vírus do sorotipo 4 foi isolado de bovinos brasileiros, mantidos em quarentena nos Estados Unidos e com sinais clínicos da doença (Groocock \& Campbell 1982). Vírus do sorotipo 12 foi isolado de um surto que ocorreu no Paraná, Brasil, em 2001 (Clavijo et al. 2002). A identificação, por meio de inquéritos sorológicos, de anticorpos contra VLA em ovinos, bovinos e caprinos demonstra que o vírus está amplamente difundido no Brasil (Pellegrin et al
1997, Melo et al. 2000, Lager 2004, Costa et al. 2006, Tomich et al. 2009). Porém, uma grande variação na soroprevalência foi observada entre as regiões, onde Norte e Sudeste tiveram maior número de animais positivos em relação à região Sul (Lobato 1999, Laender 2002, Costa et al. 2006). Na América do Sul, a doença clínica é rara e só havia sido, até agora, descrita uma vez em ovinos no estado do Paraná (Lager 2004). Este trabalho relata a ocorrência de dois surtos de língua azul em ovinos no Rio Grande do Sul e descreve as alterações clínicas e patológicas observadas nos ovinos acometidos.

\section{MATERIAL E MÉTODOS}

\section{Surto 1}

Dados epidemiológicos e sinais clínicos apresentados pelos ovinos afetados foram obtidos em visitas à propriedade. Realizou-se também o monitoramento da propriedade com acompanhamento dos casos clínicos, coleta de material para análises sorológicas, bioquímicas e virológicas. Durante a necropsia de cinco ovinos que morreram, amostras de tecidos foram coletadas e fixadas em formol tamponado a $10 \%$ por 48 horas. Posteriormente, foram processadas rotineiramente para histopatologia. Fragmento de pulmão de um dos ovinos foi encaminhado para cultivo bacteriano aeróbio. Aproximadamente $100 \mathrm{~g}$ de fígado de três animais foram coletados, congelados e encaminhados para dosagem de selênio pela técnica de espectrometria de massa acoplada a plasma induzido (ICPMS) (Alda et al. 2002). Amostras de soro dos ovinos que apresentaram sinais clínicos foram encaminhadas para o Instituto de Pesquisas Veterinárias Desidério Finamor (IPVDF) para a pesquisa de anticorpos contra o VLA, pelo teste de imunodifusão em gel de ágar (IDGA). Amostras de soro de cinco cordeiros com um mês de idade, nascidos de três ovelhas convalescentes da infecção pelo VLA, foram submetidas ao teste de IDGA para VLA. Amostras de sangue com EDTA e soro de seis animais afetados foram refrigeradas e encaminhadas para hemograma e quantificação da atividade das enzimas creatina quinase (CK) e aspartato aminotransferase (AST). Teste de duplex RT-PCR em RNA total extraído de sangue de todos os ovinos afetados foi realizado no Laboratório de Virologia da Universidade Federal de Santa Maria (LV-UFSM), com amplificação do fragmento 1156-bp do segmento 7 do genoma do VLA (Anthony et al. 2007). Os amplicons obtidos no RT-PCR foram submetidos a sequenciamento, sendo cada amplicon seqüenciado em triplicata, utilizando o DYEnamic et Dye Terminator $^{c}$ e então analisado com o Staden Package (http:// staden.sourceforge.net/). A sequência consenso foi comparada com sequências disponíveis no GeneBank utilizando o BLAST. Parte dos dados deste surto foram previamente publicados no periódico Veterinary Record (Antoniassi et al. 2010).

\section{Surto 2}

Os sinais clínicos foram obtidos com o veterinário que atendeu o ovino afetado. Apenas um entre 30 ovinos foi examinado e necropsiado. Fragmentos de tecidos deste ovino foram coletados, fixados em formol tamponado a $10 \%$ por 48 horas e processados rotineiramente para histopatologia. Fragmento de pulmão foi encaminhado para cultivo bacteriano aeróbio. Amostras de soro foram encaminhadas para a quantificação da atividade de enzimas e testes IDGA-VLA, conforme feito no surto 1. Da mesma forma como no surto 1 , amostra de sangue 
em tubo com EDTA foi encaminhada ao LV-UFSM para o teste de duplex RT-PCR, onde foi submetida ao mesmo processamento (Anthony et al. 2007).

\section{RESULTADOS}

\section{Dados epidemiológicos e clínicos}

O surto 1 ocorreu em março de 2009, em uma propriedade no município de Viamão, Rio Grande do Sul. De um total de 76 ovinos, 14 apresentaram sinais clínicos compatíveis com língua azul (Ovinos 1 a 14). Desses, oito morreram. Todos os ovinos acometidos eram da raça Texel, de ambos os sexos, com idade entre 8 meses e 4 anos. $O$ curso clínico dos ovinos que morreram variou de 2-4 dias e, nos ovinos que se recuperaram foi, em média, 15 dias. Tantos os ovinos que morreram quanto os que se recuperaram apresentaram sinais clínicos semelhantes, mas com intensidades variadas. Os sinais clínicos iniciais foram hipertermia $\left(40-41^{\circ} \mathrm{C}\right)$, apatia e prostração(Fig.1A). Dificuldade de deglutição com episódios de regurgitação, bem como secreção nasal esverdeada mucosa ou mucopurulenta (Fig.1B) foram sinais marcantes desse surto, mas outras alterações tais como erosões, úlceras e hemorragias na mucosa oral também foram observadas em alguns ovinos (Ovinos 10 a 12). No Ovino13 observou-se ainda ptose da orelha esquerda, protrusão da língua e retenção de alimento no vestíbulo esquerdo da cavidade oral (Fig.1C). O Quadro 1 sumariza dados epidemiológicos e sinais clínicos observados nesse surto. Os Ovinos 9 a 14 se recuperaram, após tratamento com dipirona sódica, penicilina e acetato de dexametasona. Nesses animais, a perda de peso foi acentuada e chegou à cifra de $25 \%$ do peso corporal, em alguns. Os Ovinos 10, 12 e 13 estavam no terço final de gestação durante a manifestação dos sinais clínicos e após a recuperação, pariram borregos sadios.

Fig.1. Ovinos infectados naturalmente pelo vírus da língua azul. (A) Ovinos apresentando apatia, prostração e tendência a manterem-se em locais sombreados. (B) Corrimento nasal mucoso esverdeado. (C) Protrusão da língua e retenção de alimento no vestíbulo da cavidade oral evidenciando disfagia.

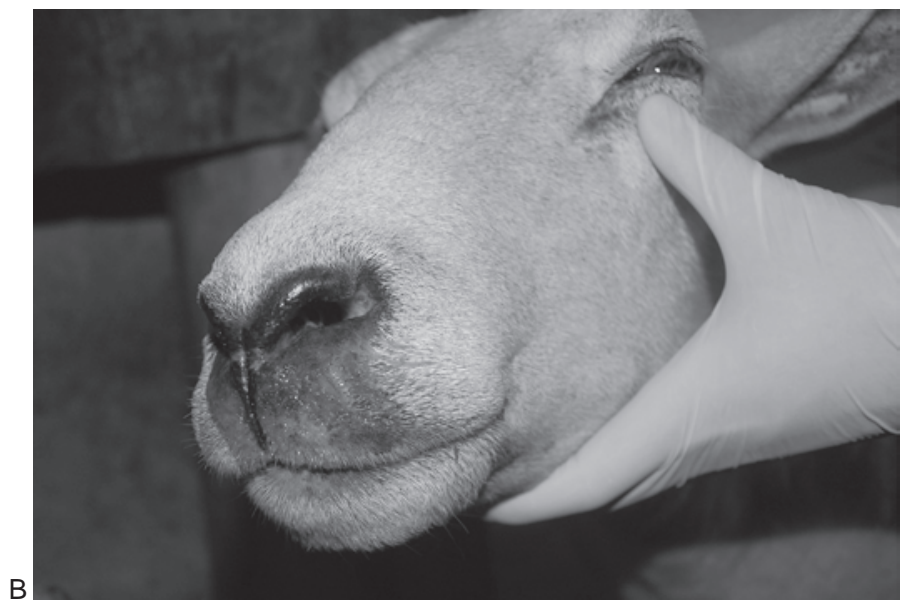

No surto 2, o Ovino 15 de dois anos, macho, da raça Texel, foi encaminhado ao Hospital de Clínicas Veterinárias da Universidade Federal do Rio Grande do Sul (HCVUFRGS) em abril de 2009, proveniente de uma propriedade do município de Glorinha. Imediatamente após o exame clínico o ovino morreu. Ao exame clínico, o animal apresentava acentuada prostração, corrimento nasal seroso profuso, dispnéia, hipertermia $\left(42^{\circ} \mathrm{C}\right)$, mucosa oral hiperêmica e úlceras no palato.

\section{Alterações macroscópicas}

Nos seis ovinos necropsiados (Ovinos 1 a 5 e 15), as alterações macroscópicas observadas incluíram secreção nasal esverdeada (todos ovinos), mucosas oculares pálidas (Ovino 15), edema subcutâneo na região da face e regiões ventrais do tórax (Ovino 1), hemorragias e úlceras na mucosa oral (Fig.2A) e conchas nasais vermelho escuras e com conteúdo alimentar (Ovino 15). Esôfago dilatado (todos ovinos) (Fig.2B) e preenchido por grande quantidade de conteúdo alimentar (Ovinos 1 a 3 e 5). Os pulmões não estavam colabados e apresentavam áreas consolidadas anteroventrais e áreas enfisematosas nos bordos (Fig.2C). Na luz de traquéia e brônquios havia conteúdo espumoso (Ovino 2) e misturado a conteúdo alimentar (Ovinos 1, 3 a 5 e 15) (Fig.2D). No coração, observaramse focos de hemorragia no epicárdio e endocárdio em to-
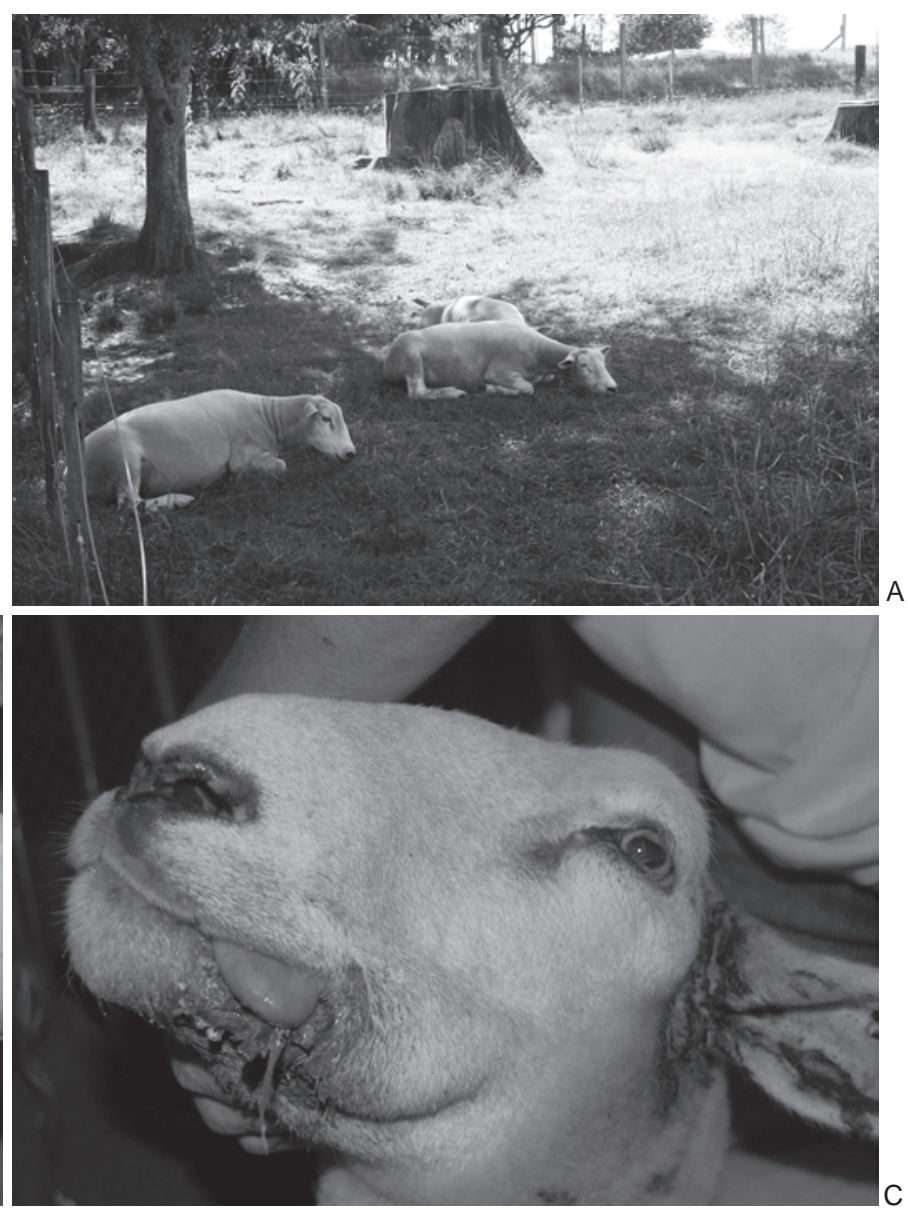


\section{Quadro 1. Aspectos epidemiológicos e clínicos da infecção pelo vírus da língua azul em ovinos no Rio Grande do Sul}

\begin{tabular}{|c|c|c|c|c|}
\hline $\begin{array}{l}\text { Identifi- } \\
\text { cação }\end{array}$ & - Idade & Sexo & Sinais clínicos & Desfecho \\
\hline 1 & 4 anos & mea & $\begin{array}{l}\text { Hipertermia, apatia, prostração, disfagia, dispnéia, aumento de volume da face, secreção nasal muco- } \\
\text { sa de coloração esverdeada. }\end{array}$ & Morte \\
\hline 3 & $8 \mathrm{me}$ & icho & $\begin{array}{l}\text { Hipertermia, apatia, prostração, disfagia, dispnéia, secreção nasal secreção nasal mucopurulenta de } \\
\text { coloração esverdeada. }\end{array}$ & Morte \\
\hline 4 & & $v$ & Hipertermia, apatia, prostração, disfagia, dispnéia, secreção nasal mucosa de coloração esverdeada. & Morte \\
\hline 5 & Adulto & & nia, apatia, prostração, disfagia, dispnéia, secreção nasal & \\
\hline 8 & Adulto & mea & , dispnéia, s & Morte \\
\hline 9 & Adulta & Fêmea & a, dispnéia, s & $\begin{array}{l}\text { Recupe- } \\
\text { ração }\end{array}$ \\
\hline 10 & 3 & $\mathrm{~F}$ & com coloração esverdea- & $\begin{array}{l}\text { Recupe- } \\
\text { ração }\end{array}$ \\
\hline 11 & $10 n$ & Macho & $\begin{array}{l}\text { nia, apatia, prostração, disfagia, dispnéia, aumento de volume da face, secreção nasal espu- } \\
\text { verdeada e abundante, úlceras na mucosa oral com odor fétido, perda de peso( } 25 \mathrm{~kg}) \text {. }\end{array}$ & $\begin{array}{l}\text { Recupe- } \\
\text { ração }\end{array}$ \\
\hline 14 & Adulto & Fêm & nacal muc & $\begin{array}{l}\text { Recupe- } \\
\text { ração }\end{array}$ \\
\hline 15 & Jov & Macho & $\begin{array}{l}\text { Hipertermia, apatia, prostração, dispnéia, corrimento nasal mucopurulenta de coloração esverdeado, } \\
\text { áreas de hiperemia e ulcerações na cavidade oral, mucosas pálidas. }\end{array}$ & Morte \\
\hline
\end{tabular}
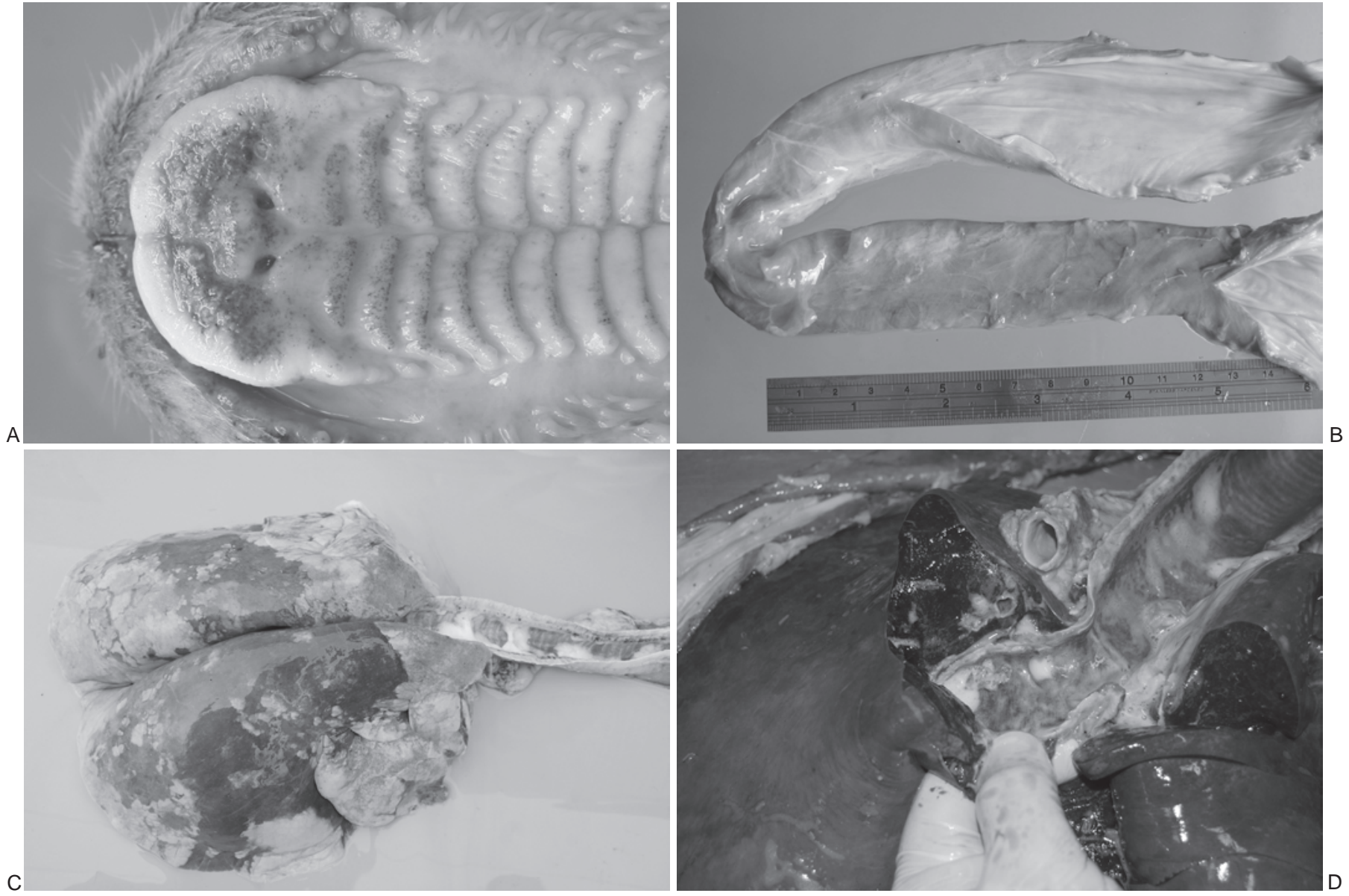

Fig.2. Ovinos infectados naturalmente pelo vírus da língua azul. (A) Áreas de erosão e hemorragia no palato duro e lábio superior.

(B) esôfago dilatado e flácido. (C) Pulmões não colapsados e vermelhos e traquéia com conteúdo espumoso abundante. (D) Luz de traquéia e brônquio com conteúdo espumoso e misturado a conteúdo alimentar. 

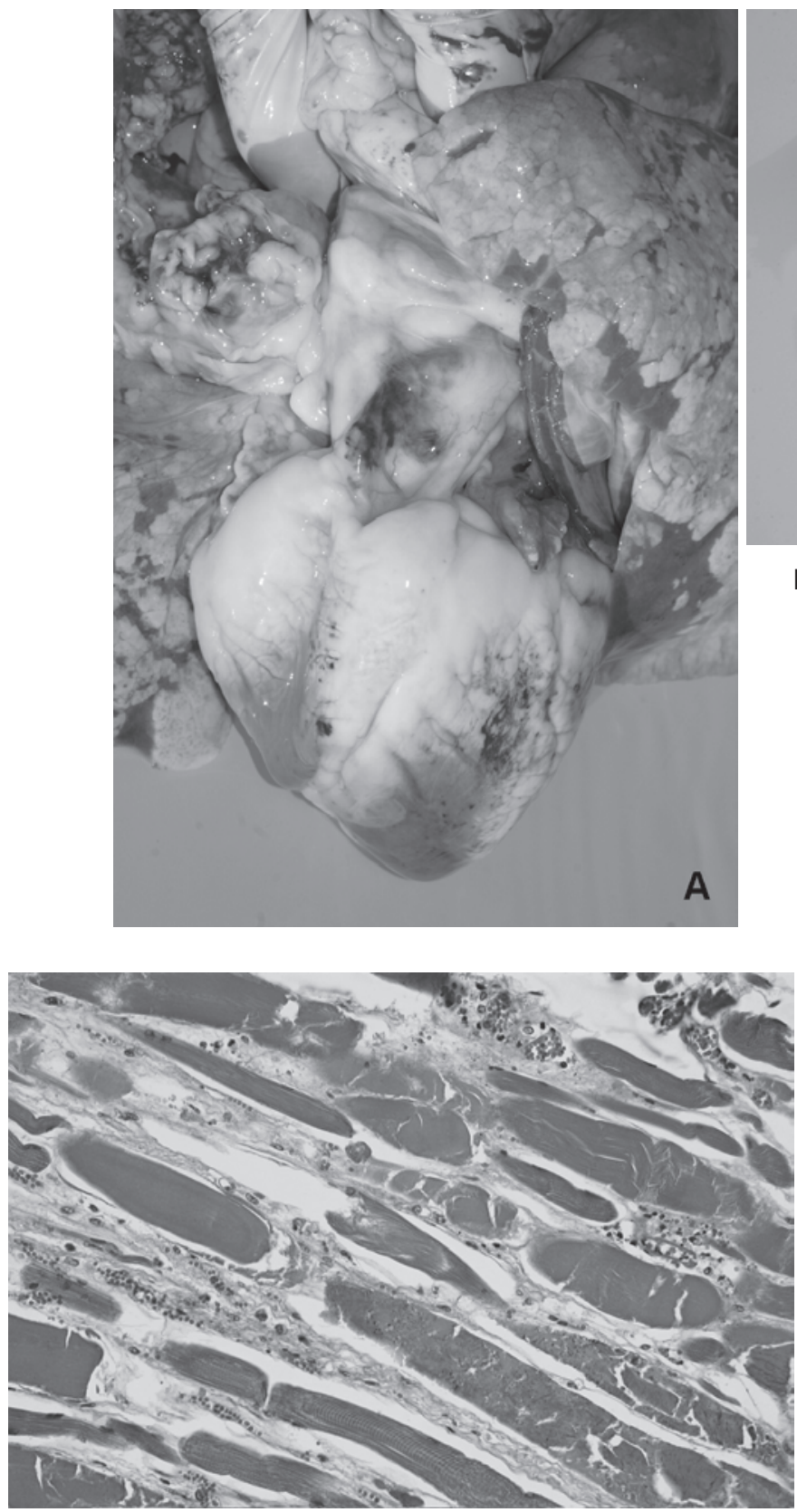

Fig.4. Músculo estriado do esôfago com degeneração hialina e flocular difusa acentuada de miofibras associada com focos de mineralização de miofibras, na infecção natural de ovino pelo vírus da língua azul. HE, obj.20x.

dos os casos, além de áreas pálidas no miocárdio no Ovino 1. Extensas áreas de hemorragia foram também observadas na base da artéria pulmonar (Fig.3A) nos seis ovinos. Observou-se ainda, no Ovino 2, fígado com coloração amarelada e no Ovino 15, rúmen e retículo com áreas hemorrágicas e ulceração da mucosa (Fig.3B).

\section{Alterações microscópicas}

As alterações observadas no tecido muscular do esôfago correspondiam a degeneração/necrose hialina e flocular bifásica leve a acentuada de miofibras associada

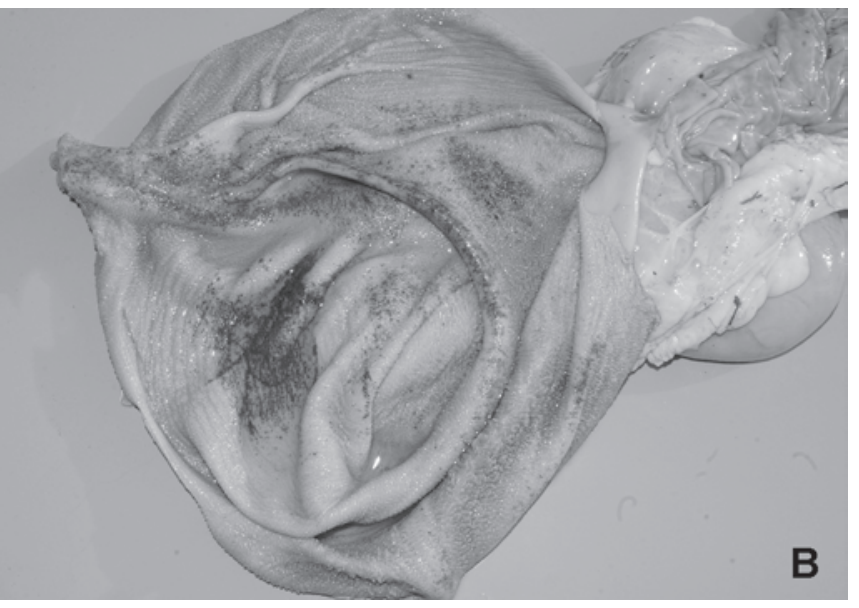

Fig.3. Ovino com infecção natural pelo vírus da língua azul. (A) Foco de hemorragia na base da artéria pulmonar. (B) Rúmen com áreas de hemorragia na mucosa.

com infiltrado inflamatório mononuclear, áreas de micromineralização de fibras musculares e focos hemorrágicos (Fig.4). Tais alterações também estiveram presentes em graus variados no miocárdio e músculos esqueléticos (serrátil cervical ventral, deltoide, semimembranáceo, semitendináceo e psoas). No endocárdio, epicárdio e base da artéria pulmonar foram observadas extensas áreas de hemorragia em todos os casos. Pneumonia aspirativa ocorreu em todos os casos, com exceção do Ovino 2, sendo microscopicamente caracterizada por infiltrado inflamatório neutrofílico difuso no interior de alvéolos, bronquíolos e brônquios associado com material vegetal e estruturas basofílicas granulares compatíveis com bactérias na luz de brônquios. Outras lesões pulmonares incluíram edema difuso acentuado, hiperemia, ocasionais focos de hemorragia, áreas de espessamento da parede alveolar de coloração eosinofílica (membranas hialinas), enfisema de bordos e edema de septos interlobulares. Outros achados incluíram hiperplasia linfoide de linfonodos, baço e tonsilas (Ovinos 2 a 4 e 15), fígado com necrose paracentral leve (Ovino 2), vacuolização hepatocelular difuso moderado (Ovino 3). O Ovino 15 apresentou também epitélio ruminal com áreas de ulceração, focos de necrose e mineralização, hemorragias, trombose e inflamação purulenta, assim como infiltrado inflamatório mononuclear na submucosa. No abomaso desse mesmo animal, havia infiltrado inflamatório focal leve e edema da submucosa acentuado; no intestino, havia encurtamento de vilosidades, necrose de criptas e infiltrado inflamatório mononuclear moderado na mucosa; os cornetos nasais estavam acentuadamente hiperêmicos.

\section{Achados laboratoriais}

Os Ovinos 10, 11, 13 e 15 foram soropositivos para o VLA no teste IDGA.

Todos os ovinos $(1,2,3,10,11,12,15)$, cujas amostras foram testadas apresentaram níveis acima dos nor- 


\begin{tabular}{|c|c|c|c|}
\hline Amostras & $\begin{array}{c}\mathrm{CK}^{\mathrm{a}} \\
(42-62 \mathrm{U} / \mathrm{L})\end{array}$ & $\begin{array}{c}\text { AST }^{\mathrm{b}} \\
(0 \mathrm{a} 90 \mathrm{U} / \mathrm{L})\end{array}$ & $\begin{array}{c}\mathrm{Se}^{\mathrm{c}} \\
(0,08-0,5 \mathrm{mg} / \mathrm{kg})\end{array}$ \\
\hline 1 & 13231,0 & 1431,24 & 0,17 \\
\hline 2 & 26088,0 & 1186,50 & 0,56 \\
\hline 3 & 620,51 & 1167 & NR \\
\hline 4 & $N R^{d}$ & NR & 0,45 \\
\hline 10 & 288,96 & 240 & NR \\
\hline 11 & 298,0 & 1185,8 & NR \\
\hline 12 & 2538,5 & 231,49 & NR \\
\hline 15 & 19067,0 & 1362,95 & NR \\
\hline
\end{tabular}

a Creatinina quinase, b aspartato amino transferase, ${ }^{c}$ selênio,

mais para as enzimas CK e AST (Quadro 2). No hemograma, nenhuma alteração foi observada. O cultivo aeróbio de fragmento de pulmão dos Ovinos 4 e 15 apresentou crescimento de flora bacteriana não patogênica. A dosagem de selênio em amostras de fígado dos Ovinos 1, 2 e 4 apresentaram níveis normais (Radostits et al. 2007). O sequenciamento dos nucleotídeos do amplicon (duplex RTPCR em material genético de VLA) identificou sequências genômicas do BTV do sorotipo 12 (homologia de nucleotídeos de 99\%).

\section{DISCUSSÃO E CONCLUSÕES}

O diagnóstico de língua azul foi estabelecido com base nos achados clínico-patológicos e confirmado pelo exame de duplex RT-PCR com a identificação do VLA, sorotipo 12. Lesões pulmonares como edema, congestão e hemorragia estão geralmente presentes em casos fulminantes da infecção pelo VLA e são relacionadas às características patogênicas de injúria microvascular causada pela ação direta do vírus e, de forma indireta, através da indução da liberação de mediadores vasoativos e inflamatórios pelo hospedeiro (Maclachlan et al. 2009). Pneumonia aspirativa é ocasionalmente associada com infecção pelo VLA como consequência de vômitos de conteúdo ruminal por diversas causas tais como edema de laringe e região pós faringeana, hemorragia de músculo pilórico, lesões ulcerativas no esôfago e faringe (Luedke et al. 1964) e paralisia do esôfago por lesão muscular (Mahrt \& Osburn 1986). A alteração mais marcante observada neste estudo foi a manifestação clínica de pneumonia associada à disfagia em grupos de animais. Em todos os animais necropsiados, a mionecrose esofágica esteve presente e associada com dilatação do esôfago e acúmulo de alimento no lúmen do órgão, o que sugere paralisia ou paresia esofagiana. Tais alterações são responsáveis por pneumonia aspirativa, geralmente fatal (Radostits et al. 2007). É provável que os ovinos que se recuperaram tenham sido afetados por uma pneumonia leve, comparada com os casos fatais, ou que a medicação administrada no início da infecção tenha sido eficaz para o controle da enfermidade.

Lesões como necrose muscular associada à minerali- zação podem lembrar as observadas em casos de distrofia muscular nutricional (DMN), causada por deficiência de selênio e vitamina E. Entretanto, a DMN é caracterizada por típicas áreas brancas com aspecto de pó de giz na superfície muscular, associada a intensa mineralização e degeneração de miócitos (Van Vleet \& Valentine 2007). Além disso, a DMN é particularmente comum em animais jovens de crescimento rápido, nascidos de fêmeas que foram alimentadas com dietas deficientes de selênio e vitamina E por longo período (Radostits et al. 2007, Van Vleet \& Valentine 2007). Baixos níveis desses nutrientes em tecidos e na dieta são utilizados para a confirmação do diagnóstico de DMN. Os três ovinos desse estudo submetidos à dosagem de selênio em amostras de fígado apresentaram níveis normais do nutriente (Radostitis et al 1994). Adicionalmente, lesões típicas de língua azul, como hemorragias multifocais, em especial a encontrada na base da artéria pulmonar, dita como patognomônica da doença, áreas de edema e lesões isquêmicas principalmente em tecido muscular (Maclachlan et al. 2009) estiveram presentes e foram consistentes com o resultado do teste de RT-PCR e sequenciamento, confirmando o diagnóstico. Os resultados positivos do AGID-VLA foram utilizados na demonstração do contato dos animais com o vírus.

O aumento da enzima CK no soro é uma indicação específica de lesões em musculatura cardíaca e esquelética. O Aumento da AST também pode ser utilizado como indicador de lesões musculares, porém não tão específico (Cardinet 1997). Todos os ovinos testados apresentaram aumentos nos níveis das duas enzimas. Entretanto, esses foram mais elevados nos animais que morreram, confirmando a maior extensão das lesões musculares nesses animais. O cultivo aeróbio de fragmento de pulmão realizado apresentou crescimento de flora bacteriana mista não patogênica, o que caracteriza uma infecção oportunista. A bactéria mais comumente associada à pneumonia aspirativa em casos de língua azul é Pasteurella sp. (Luedke et al. 1964, Mahrt \& Osburn 1986). Infecção fetal causada pelo VLA tem sido relatada nos Estados Unidos e na África do Sul e associados com o uso de vacinas vivas modificadas (Maclachlan et al. 2000). No mínimo quatro sorotipos de VLA (VLA-10, VLA-11, VLA-13 e VLA-17) já foram descritos como hábeis a cruzar a placenta e causar infecção fetal (Maclachlan et al. 1985). Quando essa infecção ocorre, alterações como aborto, deformidades congênitas como hidrocefalia e nascimento de animais virêmicos são observados (Hourrigan \& Klingsporn 1975). No presente estudo, três das ovelhas que adoeceram e que foram positivas no teste de IDGA para o VLA (Ovinos 10, 12 e 13) estavam no final da gestação e pariram cordeiros normais aproximadamente um mês após a recuperação. Os cinco cordeiros testados para o VLA pelo teste de IDGA, ao primeiro mês de vida, foram sorologicamente negativos, demonstrando a não transmissão e infecção do vírus para os fetos.

Em estudos soroepidemiológicos para VLA realizados no Brasil, o estado do Rio Grande do Sul apresentou a menor soroprevalência em relação aos outros estados, o que 
pode ser associado com as condições climáticas locais desfavoráveis à manutenção do vetor (Costa et al. 2006). 0 grande número de animais soronegativos na região associado com mudanças climáticas que favoreçam a proliferação do vetor, ou a introdução de um novo sorotipo pode ser responsável pela ocorrência da doença clínica. O sorotipo 12 e o 4 foram os únicos isolados e associados com doença clínica na América Latina (Groocock \& Campbell 1982, Clavijo et al. 2002). Uma possível recente introdução do sorotipo 12 na região, assim como a possibilidade de maior virulência desse sorotipo devem ser investigados.

Agradecimentos.- Aos professores Cláudio Barros (UFSM), Pedro Bezerra (UFLA) e Cláudio Cruz (UFRGS), pela revisão desse artigo. À Coordenação de Aperfeiçoamento de Pessoal de Nível Superior (CAPES) e ao Conselho Nacional de Desenvolvimento Científico e Tecnológico (CNPq, Proc.558951/2010-4), pelo apoio financeiro.

\section{REFERÊNCIAS}

Alda A.M.R., Colón J.L.L \& Lobón J.M.P. 2002. Metodología recomendada para la medición del contenido de selenio en especímenes biológicos. Química Clínica 21:67-73.

Alfieri A.A., Alfieri A.F., Takiuchi E. \& Lobato Z.I.P. 2007. Reoviridae, p.773-807. In: Flores E.F. (Ed.), Virologia Veterinária. Editora da Universidade Federal de Santa Maria, Santa Maria.

Anthony S., Jones H., Darpel K.E., Elliot H., Maan S., Samuel A., Mellor P.S. \& Mertens P.P.C. 2007. A duplex Rt-Pcr for detection of genome segment 7 (Vp7 Gene) from 24 Btv serotypes. J. Virol. Methods 141:188-197.

Antoniassi N.A.B., Pavarini S.P., Henzel A., Flores E.F. \& Driemeier D. 2010. Aspiration pneumonia associated with oesophageal myonecrosis in sheep due to BTV infection in Brazil. Vet. Rec. 166:5253.

Cardinet G.H. 1997. Skeletal muscle function, p.407-440. In: Kaneko J.J. (Ed.), Clinical Biochemistry of Domestic Animals. $5^{\text {th }}$ ed. Academic Press, London.

Clavijo A., Sepulveda L., Riva J., Pessoa-Silva M., Tailor-Ruthes A. \& Lopes J.W. 2002. Isolation of Bluetongue Vírus serotype 12 from an outbreak of the disease in South America. Vet. Rec. 151:301-302.

Costa J.R.R., Lobato Z.I.P., Hermann G.P., Leite R.C. \& Haddad J.P.A. 2006. Prevalência de anticorpos contra o vírus da língua azul em bovinos e ovinos do sudoeste e sudeste do Rio Grande do Sul. Arq. Bras. Med. Vet. Zootec. 58:273-275.

Groocock C.M. \& Campbell C.H. 1982. Isolation of an exotic serotype of bluetongue virus from imported cattle in quarantine. Can. J. Comp. Med. 46:160-164.

Holfmann M.A., Renzullo S., Madder M., Chaignat V. \& Worwa G. 2008. Genetic characterization of Toggenberg orbivirus, a new bluetongue virus from goats. Switzerland. Emerging Infect. Dis. $14: 1855-1861$
Hourrigan J.L. \& Klingsporn A.L. 1975. Bluetongue: The disease in cattle. Aust. Vet. J. 51:170-174.

Laender J.O. 2002. Língua azul em rebanhos de ovinos e caprinos em três mesoregiões de Minas Gerais: análise de envidência clínica e sorológica e identificação de Culicoides sp. Dissertação de Mestrado, Escola de Veterinária, Universidade Federal de Minas Gerais, Belo Horizonte. 92p.

Lager I.A. 2004. Bluetongue virus in South America: Overview of viruses, vectors, survillance and unique features. Vet. Ital. 40:89-93.

Lobato Z.I.P. 1999. Língua azul: a doença nos bovinos. Revta Bras. Reprod. Anim. 23:515-523.

Luedke J., Bowne J.G., Jochim M. \& Cora Doyle B.S. 1964. Clinical and pathologic features of Bluetongue in sheep. Am. J. Vet. Res. 25:963-970.

MacLachlan N.J., Conley A.J. \& Kennedy P.C. 2000. Bluetongue and equine viral arteritis viruses as models of virus-induced foetal injury and abortion. Anim. Reprod. Sci. 60/61:643-651.

MacLachlan N.J., Drew C.P. Darpel K.E. \& Worwa G. 2009. The pathology and pathogenesis of bluetongue. J. Comp. Pathol. 141:116.

MacLachlan N.J., Osburn B.I., Stott J.L. \& Ghalib H.W. 1985. Orbivirus infection of the bovine foetus. Prog. Clin. Biol. Res. 178:79-84.

Mahrt C.R. \& Orburn B.I. 1986. Experimental bluetongue virus infection of sheep; effect of vaccination: Pathologic, immunofluorescent, and ultrastructural studies. Am. J. Vet. Res. 47:1198-1203

Melo C.B., Oliveira A.M., Azevedo E.O., Lobato Z.I.P. \& Leite R.C. 2000. Anticorpos contra o vírus da língua azul em bovinos do sertão da Paraíba. Arq. Bras. Med. Vet. Zootec. 52:19-20

Pellegrin A.O., Sereno J.R.B., Leite R.C. \& Figueiredo H.C.P. 1997. Doenças da reprodução de bovinos no Pantanal: ocorrência de animais soropositivos para os vírus da rinotraqueíte infecciosa bovina, diarréia bovina a vírus e lingua azul. Comum. Téc. 20, Embrapa Pantanal, Corumbá. $7 p$

Radostits O.M., Blood D.C. \& Gay C.C. 1994. Veterinary Medicine: A textbook of the diseases of cattle, horses, sheep, pigs, and goats. $8^{\text {th }}$ ed. Baillière Tindall, London, p.1368-1453.

Radostits O.M., Gay C.C., Hinchcliff K.W. \& Constable P.D. 2007. Veterinary Medicine: A textbook of the diseases of cattle, horses, sheep, pigs, and goats. $10^{\text {th }}$ ed. Saunders Elsevier, Philadelphia, p.1691-1783.

Tomich R.G.P., Nogueira M.F., Lacerda A.C.R., Campos F.S., Tomas W.M., Herrera H.M., Lima-Borges P.A., Pellegrin A.O., Lobato Z.I.P., Silva R.A.M.S., Pellegrin L.A. \& Barbosa-Stancioli E.F. 2009. Sorologia para o vírus da língua azul em bovinos de corte, ovinos e cervos campeiros no pantanal sul-mato-grossense. Arq. Bras. Med. Vet. Zootec. 61:1222-1226.

Van Vleet J.F. \& Valentine B.A. 2007. Muscle and Tendon, p.185-280. In: Maxie M.G. (Ed.), Jubb, Kennedy and Palmer's Pathology of Domestic Animals. Vol. 1. $5^{\text {th }}$ ed. Saunders Elsevier, Philadelphia.

Verwoerd D.W. \& Erasmus B.J. 2004. Bluetongue, p.1201-1220. In: Coetzer J.A.W. \& Tustin R.C. (Eds), Infectious Disease of Livestock. Vol.2. $2^{\text {nd }}$ ed. Oxford Univertsity Press, Cape Town. 